\title{
Development of Student Competencies Overtime in an Authentic Immersive Design Experience
}

\section{Prof. Zahed Siddique, University of Oklahoma}

Zahed Siddique is a Professor of Mechanical Engineering at the School of Aerospace and Mechanical Engineering of University of Oklahoma. His research interest include product family design, advanced material and engineering education. He is interested in motivation of engineering students, peer-to-peer learning, flat learning environments, technology assisted engineering education and experiential learning. $\mathrm{He}$ is the coordinator of the industry sponsored capstone from at his school and is the advisor of OU's FSAE team.

\section{Prof. Farrokh Mistree, University of Oklahoman, Norman}

Farrokh's passion is to have fun in providing an opportunity for highly motivated and talented people to learn how to define and achieve their dreams.

Farrokh Mistree holds the L. A. Comp Chair in the School of Aerospace and Mechanical Engineering at the University of Oklahoma in Norman, Oklahoma. Prior to this position, he was the Associate Chair of the Woodruff School of Mechanical Engineering at Georgia Tech - Savannah. He was also the Founding Director of the Systems Realization Laboratory at Georgia Tech.

Farrokh's current research focus is model-based realization of complex systems by managing uncertainty and complexity. The key question he is investigating is what are the principles underlying rapid and robust concept exploration when the analysis models are incomplete and possibly inaccurate? His quest for answers to the key question are anchored in three projects, namely,

Integrated Realization of Robust, Resilient and Flexible Networks

Integrated Realization of Engineered Materials and Products

Managing Organized and Disorganized Complexity: Exploration of the Solution Space

His current education focus is on creating and implementing, in partnership with industry, a curriculum for educating strategic engineers-those who have developed the competencies to create value through the realization of complex engineered systems.

Email < farrokh.mistree@ ou.edu > URL http://www.ou.edu/content/coe/ame/people/amefaculty/mistree.html LinkedIN http://www.linkedin.com/pub/farrokh-mistree/9/838/8ba

\section{Mr. Lucas Balmer, University of Oklahoma}

Lucas Balmer is a second year master's student at the University of Oklahoma studying mechanical engineering. He has been working as a graduate teaching assistant for three semesters in design orientated courses. With this experience he is working on his thesis titled "A Framework for Designing Courses that Support Design Thinking." After graduation Lucas plans to work in the automotive industry.

\section{Dr. Warren F Smith, UNSW, Canberra, Australia}

Dr Warren Smith is a Senior Lecturer in the School of Engineering and Information Technology, University of NSW at the Australian Defence Force Academy, Canberra. He joined UNSW in 1998 and has teaching responsibilities in Mechanical Engineering Design and Naval Architecture.

Prior to joining UNSW, he spent 20 years as a Naval Architect with the Australian Department of Defence (Navy). He holds a BE (Naval Architecture), a MS (Mechanical Engineering) and a PhD (Operations Research).

Dr Smith's technical research interests span systems design and design optimisation in the domains of Mechanical Engineering and Naval Architecture. He is also very interested in Engineering Design Education. Dr Smith is passionate about authentic, immersive and project-based learning in the context of engineering design education, being strongly of the opinion that design is learnt through doing. 


\title{
Development of Student Competencies Overtime in an Authentic Immersive Design Experience
}

\begin{abstract}
Background: Undergraduate students in engineering mostly encounter problems that have unique solutions and are well defined. In their professional life they are most likely to encounter problems that are ill-structured. Hence, in AME4163 Principles of Engineering Design, we strive to provide an opportunity for students to learn and internalize the principles of design and to develop competencies to help them succeed in their careers. Salient features of AME4163 include an authentic, immersive experience and scaffolding of learning via structured assignments and lectures.
\end{abstract}

Purpose: In this paper we focus on the development of competencies by students using an authentic, immersive experience. The course is scaffolded and explicitly focuses on student learning and development of competencies throughout the semester. In this paper we track changeover-time of development of student competencies, specifically related to team, communication, and design process, for a better understanding of the effects of assignments on development of competencies.

Method: An instrument was developed and administered to the students in the course for selfreported evaluation of competencies. After each assignment a survey was given to the students to express their understanding of the new tools and concepts, and development of related competencies. Some of the items of the instrument were modified to reflect the assignments. In this paper we focus on the results of the competencies.

Results: The data gathered through the instrument indicate that self-reported level of developed competencies fluctuated throughout the semester. Senior students in mechanical engineering in AME 4163, in most instances, perceived to have well-developed competencies from the beginning of the semester. A positive influence was found on competencies related to the design process. Competencies related to managing a team and communication stay steady or show a decline. These are areas that indicate the need for improvement in the course.

Conclusions: Data driven analysis provides us with the information we need to continuously improve the course. In the areas where students have indicated an improvement of competence the course was effective. For the areas where the students showed no improvement we recognize the need to modify the course and in the last section we have identified possibilities.

Keywords: Student competency; design course; team competency

\section{Frame of reference}

The competitiveness of the U.S., which is linked to standard of living, is dependent on our ability to produce a large number of sufficiently innovative engineers ${ }^{1-5}$. Serious concerns have been 
raised about whether the U.S. is adequately preparing the next generation ${ }^{6}$ for the demands of an increasingly high-tech and interdisciplinary workplace, and whether enough scientists, engineers, and highly skilled workers are being produced ${ }^{7-8}$. To prepare and educate this workforce, we need to understand the career demands they will face and for which they need to be prepared.

Instructors in most undergraduate courses in engineering have students solve problems that are well defined, with the dimensions, materials, forces, etc., being specified. In the world of practice our students will encounter problems that are ill-structured. Hence, we strive to provide an opportunity for students to learn how to internalize the principles of design and to develop competencies to tackle ill-structured problems through an authentic, immersive experience that involves designing, building and testing a mechanism. Engineering educators need to rise to the challenge of equipping students with foundational math and science skills and ensuring that they are able to use them to successfully address novel and complex problems and challenges. The engineering education curriculum needs to be anchored in mathematics and sciences, emphasizing the professional role of the engineer and demanding new competencies suited for newly emerging world contexts, with innovation, interdisciplinary and complex problems being a central theme ${ }^{1-5}$. We can move this curriculum forward by specifically focusing on design and assessment of instructional activities that address the engineering metacompetencies ${ }^{9}$.

Engineering programs usually do not assess competencies of students, rather the focus is on grades based on examinations that require them to solve well defined problems. The exception being design courses, where students address ill-structured problems. Design courses in engineering play a crucial role to develop and improve competencies needed by students to excel in the $21 \mathrm{st}$ century workplace. Assessing student competencies can be a challenging task, hence in this paper we present the use of surveys to identify self-reported student competencies to assess development of competencies.

In AME4163, Principles of Design, we orchestrate learning through an authentic and immersive learning experience. The ill-structured problem takes the form of a design, build and test project. Salient features of the course include: self-organized teams, scaffolded assignments that are anchored in experiential learning, and being treated as junior engineers. Our aim in this course is to prepare students for industry sponsored senior capstone (short term) and careers in industry (long term). Hence, after each assignment the students are surveyed to ascertain their understanding of the material, level of competence, and asked to write learning statements. Learning statements are used to ensure that students think about learning more explicitly. Learning statements are completed through experiential learning and are written in the form shown in the bottom of Figure 1. 


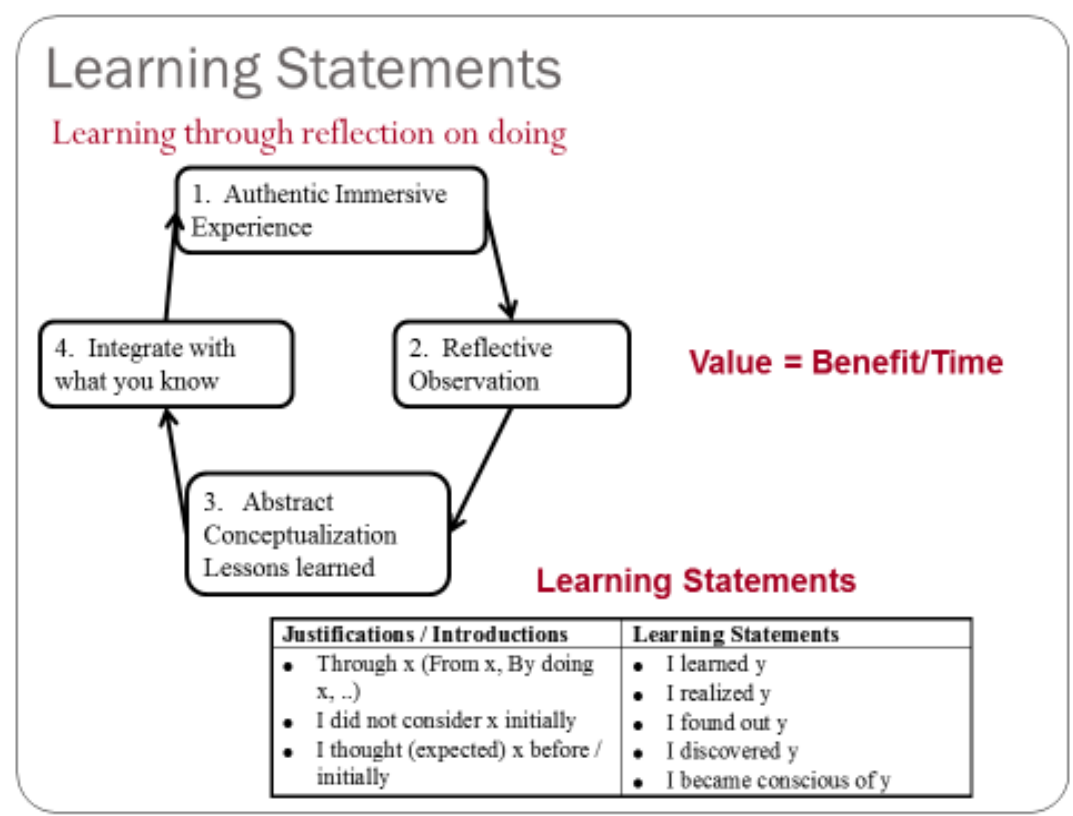

Figure 1: Learning Statement Structure

Our objective in this paper is to understand the effects of authentic design problems on development of student competencies. We track the change overtime of student competencies using self-reported student data. The collected information on student competencies can serve as a baseline, so that AME4163 can be improved to enhance learning and the development of career sustaining competencies by our graduates. In the following section the basis of competency learning is discussed as well as the reasoning behind the selection of competencies used in this paper. Then we describe the salient features of AME4163, followed by the self-reported instrument, surveys, and its administration. Finally, we summarize our findings and suggest a way forward with the course.

\section{Technical competencies and metacompetencies}

The nature of innovation is changing. A large body of evidence suggests that raw production of ideas alone is no longer sufficient for accomplishing innovation. The innovators of the future will need to be equipped with more than just specialization skills ${ }^{10}$. A competency based curriculum needs to focus on the relationship between the engineer and his/her work environment, current and future. Consequently, the set of competencies needed in engineers needs to be identified first.

The problems that we have today are global and complex in nature, where engineers need to manage dilemmas that arise through the interactions of economic, social, ecological, and intellectual capital. Specifically, innovations in the future will increasingly come from teams of collaborators who can bring together multiple skills and perspectives. The competencies required by engineers will have to support innovations that go beyond the current models of only economic capital. Unfortunately, too little formal investigation and understanding exists to help identify appropriate competencies needed by engineers for the innovation economy. 
There are two levels of competencies in any professional field, field-specific task competencies, and generalized skill sets, or meta-competencies. The task-specific competencies are benchmarks for graduates in a given field that define them as well-prepared to meet job demands and excel in the future ${ }^{11}$. The general (meta) competencies are skill sets that enable them to function globally, such as to work with others, function in systems and meet organizational demands, and transfer task-specific skills to novel problems or tasks they have not encountered before ${ }^{12}$. The development of competencies to support engineering specifically, and innovation more globally, is spiral in nature, with students building on some and adding new ones as they progress through the curriculum. A set of metacompetencies, complied by various educators and researchers ${ }^{11}{ }^{12}$, that engineers will need are listed in Table 1.

\section{Table 1: Categories of Competencies}

\begin{tabular}{|c|c|}
\hline \multicolumn{2}{|c|}{$\begin{array}{cl}\text { Manage Information } \\
\text { - } & \text { Gather information } \\
\text { - } & \text { Interpret information } \\
\text { - } & \text { Validate information } \\
\text { - } & \text { Use information } \\
\text { - } & \text { Understand quantitative } \\
& \text { and qualitative } \\
\text { information Discard } \\
\text { useless information }\end{array}$} \\
\hline Man & ye Learning \\
\hline & $\begin{array}{l}\text { Ability to interact with } \\
\text { multiple modes of } \\
\text { learning } \\
\text { Learning throughout life } \\
\text { Ability to self-instruct } \\
\text { and self-monitor learning }\end{array}$ \\
\hline & $\begin{array}{l}\text { Cottitude } \\
\text { Coping with chaos } \\
\text { Acknowledge mistakes } \\
\text { and un-productive paths } \\
\text { Integrity } \\
\text { Risk taking } \\
\text { Decisiveness } \\
\text { Optimism } \\
\text { Persistence }\end{array}$ \\
\hline
\end{tabular}

\author{
Manage Thinking \\ - Think across disciplines \\ - $\quad$ Rising above the micro and \\ fragmentary and acquiring a \\ bigger picture of things \\ - Conceptual thinking \\ - Kaleidoscopic thinking \\ - Avoid excessively broad or \\ narrow generalizations, or \\ confusion from cross-coupling \\ - Critical discussion \\ - Think strategically through \\ theory and methods. \\ - To explore opportunities for \\ developing breakthrough \\ products, systems or services \\ Manage Collaboration \\ - Manage the \\ interorganizational \\ collaboration process \\ - Create new knowledge \\ collaboratively \\ - Negotiating competence \\ - Teamwork competence
}

In this paper we assess, using self-reported student surveys, the development of student competencies in a design course. From the competencies in Table 1 the ones we have selected to explore are understanding requirements, teamwork competence from an individual and team manner, communication, and understanding the design process. These have been selected because of their importance in our graduates developing appropriate career sustaining skills. The ability to understand requirements is critical to being able to design a successful product. Without being able to encompass the proper requirements the product will not be successful. Being able to manage and work in a team setting are crucial to having a successful team complete a project. 
Understanding the design process helps with the development of novel ideas that lead to innovative and inexpensive solutions.

\section{Selected design course: AME 4163 - Principles of Design}

AME4163 Principles of Engineering Design is a senior level mechanical engineering design course at the University of Oklahoma. In this course through appropriate scaffolding, students are provided with an opportunity to explore and experience issues and tools related to design in an authentic and immersive environment. To make the experience authentic the students are treated as if they are junior engineers within a company empowered to learn through doing. The problem given is vague on purpose as to reflect a real world issue. This forces the students to make and justify engineering decisions on how to proceed. To make the experience immersive the students are inputted into the fictitious world of Planet Vayu* Here they are solving a problem that is plaguing the planet. They are provided with a background of the problem and how it is affecting the planet. They are asked to understand the needs of the community, designer, manufacturer, and any other possible needs. The scaffolding provided through the class included an outline of the design process the students follow given during each lecture to show where the new information takes place. Also in each assignment the inputs and outputs are shown -bringing over the information from the previous assignment that they will use for the current one. An example of the scaffolding can be seen in Figure 2.

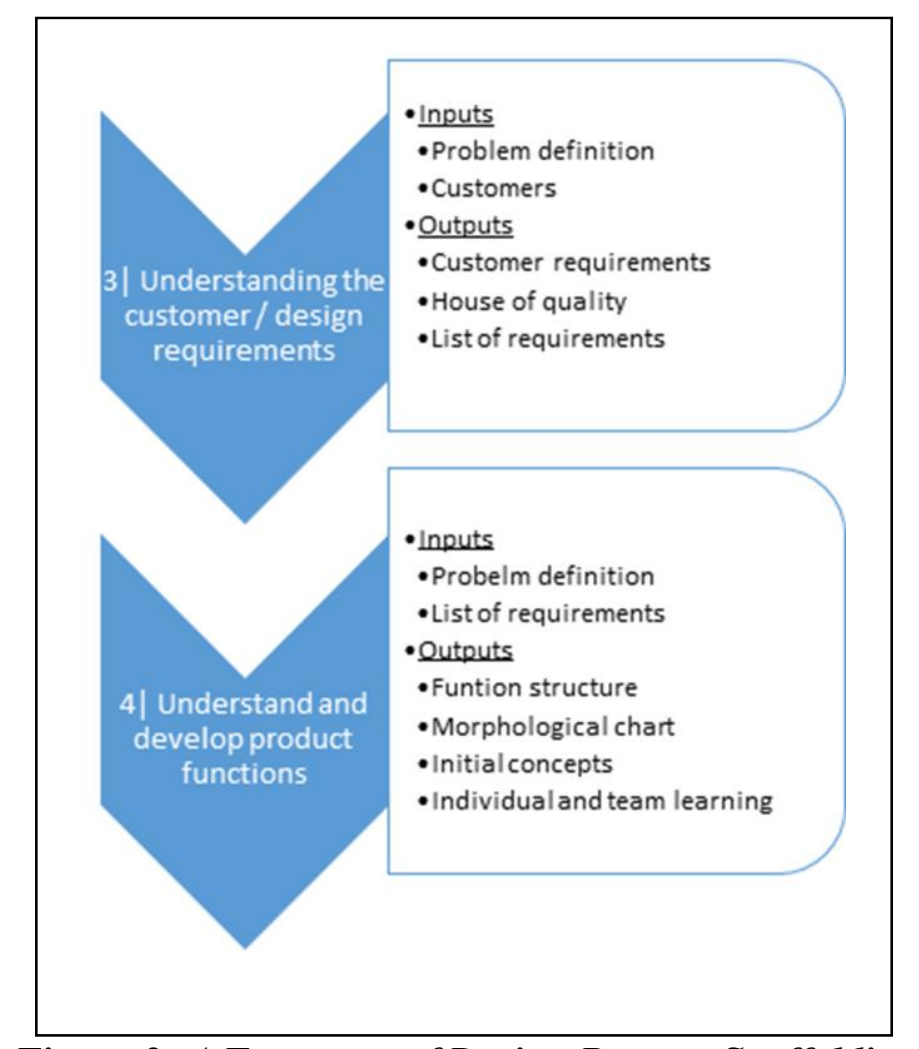

Figure 2: A Fragment of Design Process Scaffolding

* Dr. Jon A. Shupe, while a doctoral candidate in the Department of Mechanical Engineering in the eighties, wrote a booklet titled "Vayun Capers." PSHARK: Speilbaum's Hasty Amphibious Retrieval of Klepp is one of the vignettes in Vayun Capers. 
The students form self-organized teams are then guided through an authentic and immersive conceive-design-build-test-and-reflect experience, with an emphasis on the development of digital prototypes and using them for analysis. In AME4163, a design process that combines steps from several general prescriptive models for designing is introduced to the students ${ }^{13}$. The steps of the design process are shown in Figure 3.

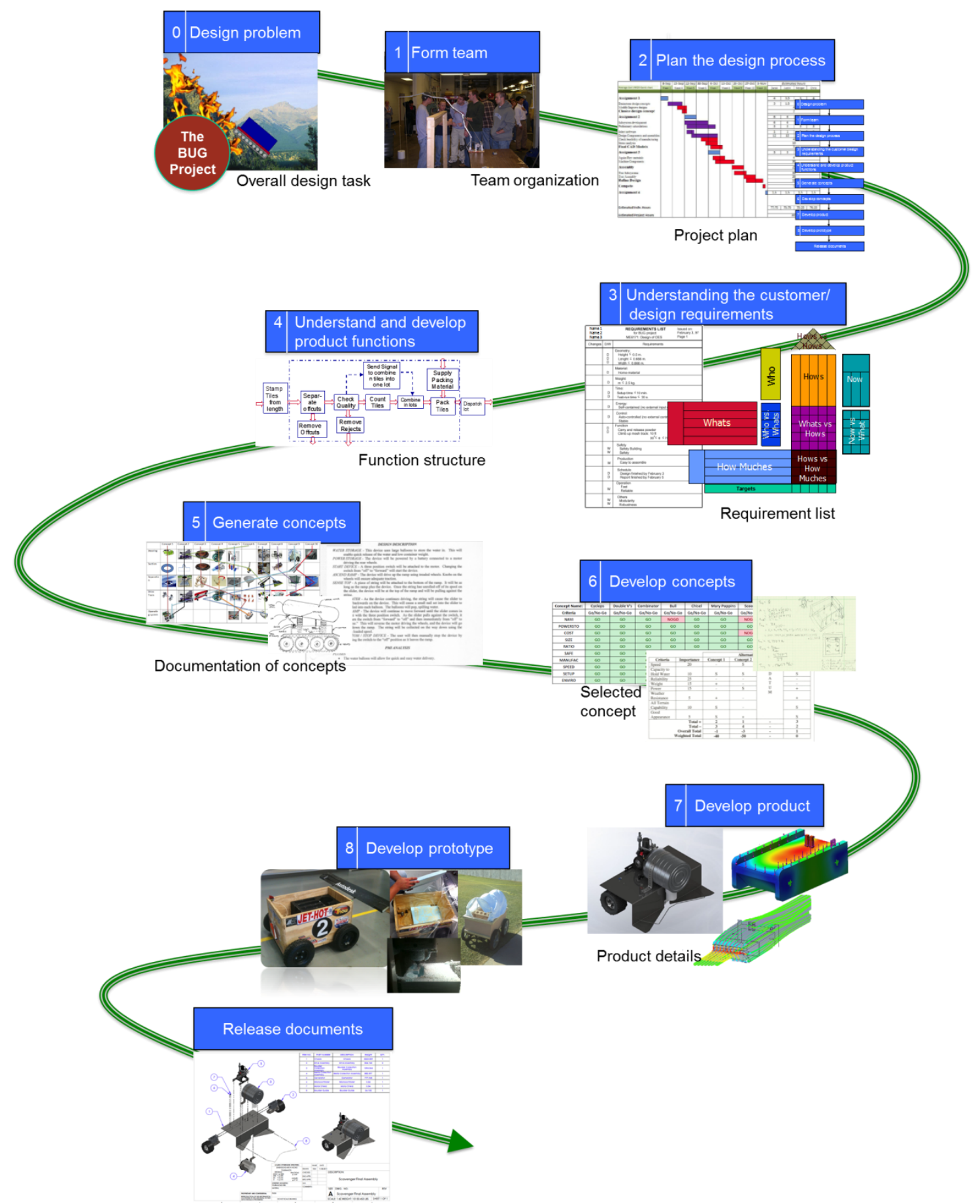

Figure 3: Design Process used in AME 4163 
In Fall 2014, the students were provided with the opportunity to learn the principles of design by designing, building and testing a mechanism - SHARK. Specifically, they were required to design, build and test a SHARK system capable of moving overland a distance of eight (8) feet, and then enter a harbor, (modeled in this instance by a child's wading pool.) The SHARK must cover the eight (8) feet as rapidly as possible. Upon entering the 'harbor' the SHARK must retrieve as much Klepp as possible within set time limits. Contained in Figure 4 are the initial restrictions and the testing area that were given to the students. As students go through this experience we expect them to develop competencies to help them solve open problems that they will encounter in their career. This course serves as an opportunity to work in groups and develop team competencies. Also when they present ideas or concepts they learn how to effectively communicate with others in a team setting.

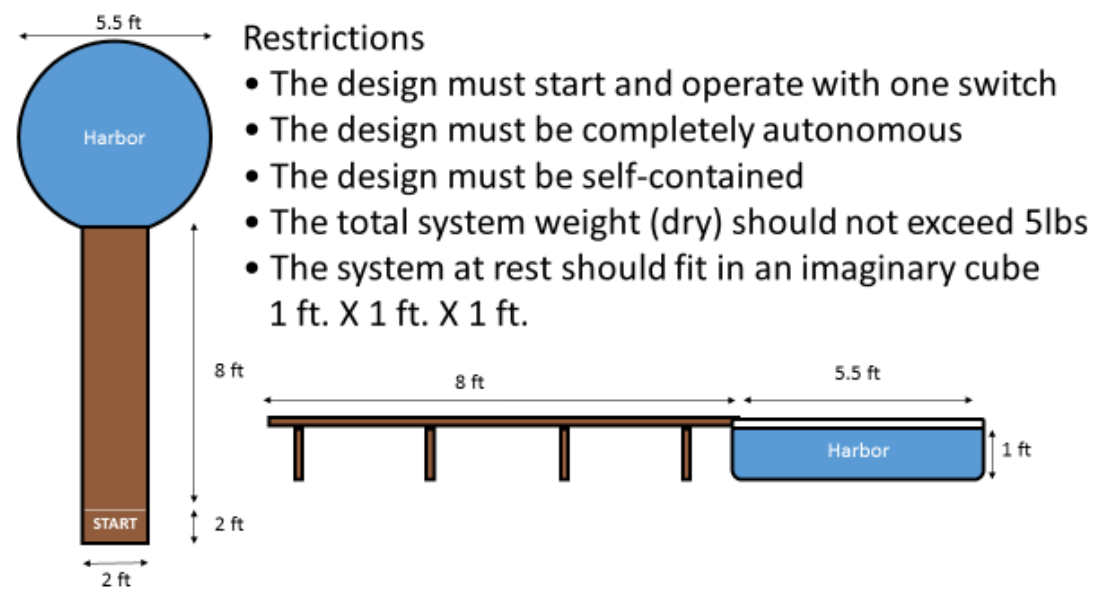

Figure 4: Project SHARK Restrictions

\section{Method and results}

\section{Instrument - self-reported engineering competency development}

The students were surveyed throughout the semester as they completed different assignments related to design of a product. The items of the instrument gauged student perception of their development of competencies related to understanding requirements, teamwork competence from an individual and team manner, communication, and understanding the design process. The authentic design problem that the students addressed in the class required them to use concepts, knowledge, and tools that they have been introduced to during their previous six semesters.

In this paper we investigate the following competencies (Table 3): (A) Understanding requirements of a project (B) Managing a team (team) (C) Managing a team (individual) (D) Communication (E) Understanding design process. The items used in the instrument are shown in Table 2. Students used a Likert scale of 1-7 (Very Poor - Very Well) to answer questions of the instrument. These questions were submitted to the students in the same format and manner throughout the semester. Shown in Table 2 is an overview of the questions administered to the students. 
Table 2: Items of Self-Reported Engineering Competency Development Instrument

\begin{tabular}{|c|l|}
\hline & $\begin{array}{l}\text { At this stage of Project SHARK and from your perspective, how well did the team work } \\
\text { together on various aspects of the project? }\end{array}$ \\
\hline Q1 & Understanding the requirements \\
\hline Q2 & Meeting together \\
\hline Q3 & Listening to everyone's ideas \\
\hline Q4 & Decision making \\
\hline Q5 & Written communication \\
\hline Q6 & Design documentation \\
\hline & $\begin{array}{l}\text { Please answer the questions to the best of your ability. Please respond regarding how true } \\
\text { each statement is for you, from your perspective, } \text { using the following response scale: }\end{array}$ \\
\hline Q7 & I am confident in my ability to establish roles and responsibilities in a team environment \\
\hline Q8 & I am confident in my ability to set modes of operation for productive teamwork \\
\hline Q9 & I am confident in my ability to resolve conflict in a team environment \\
\hline Q10 & I am confident in my ability to communicate my perspectives and concepts to my team \\
\hline Q11 & I am confident in my ability to build team consensus to make decisions \\
\hline Q12 & I am confident in my ability to identify steps needed for successful design \\
\hline Q13 & $\begin{array}{l}\text { I am confident in my ability to logically structure and manage the steps needed for } \\
\text { successful design }\end{array}$ \\
\hline Q14 & $\begin{array}{l}\text { I am confident in my ability to identify the resources needed to complete the steps in a } \\
\text { design process }\end{array}$ \\
\hline Q15 & $\begin{array}{l}\text { I am confident in my ability to properly allocate the resources needed to complete the steps } \\
\text { in a design process }\end{array}$ \\
\hline Q16 & I am confident in my ability to develop a Problem Statement \\
\hline
\end{tabular}

Table 3: Grouping of Questions According to Competencies

\begin{tabular}{|c|l|c|}
\hline & \multicolumn{1}{|c|}{ Grouping } & Questions \\
\hline A & Understanding Requirements & 1,16 \\
\hline B & Managing a Team (As a Team) & $2,3,4$ \\
\hline C & Managing a Team (As an Individual) & $7,8,9,11$ \\
\hline D & Communication & $5,6,10$ \\
\hline E & Understanding Design Process & $12,13,14,15$ \\
\hline
\end{tabular}

\section{Administration of instrument}

Five surveys were given to gauge the development and track change-over-time of student competencies through the senior level design course. Students were given one week to complete the survey, after they completed the relevant assignment. Desire to Learn (OU's Learning Management System) was used to administer the instrument throughout the semester. The timeline of the administration of the survey and assignments are shown in Table 4. 
Table 4: Course Assignments and Administration of Instrument

\begin{tabular}{|c|c|c|c|c|}
\hline & Design Steps & Outcome & Assignment & Survey \\
\hline 1 & Form team & $\begin{array}{l}\text { Team } \\
\text { organization }\end{array}$ & \multirow{2}{*}{$\begin{array}{l}\text { A1: Team formation and planning: } \\
\text { Form team, create team contract, } \\
\text { understand problem }\end{array}$} & \multirow[b]{2}{*}{1} \\
\hline 2 & Plan the design process & Project plan & & \\
\hline 3 & $\begin{array}{l}\text { Understanding the } \\
\text { customer/design } \\
\text { requirements }\end{array}$ & $\begin{array}{l}\text { Requirements } \\
\text { list }\end{array}$ & $\begin{array}{l}\text { A2: Understanding customer } \\
\text { requirements: Create house of quality } \\
\text { and list of requirements }\end{array}$ & 2 \\
\hline 4 & $\begin{array}{l}\text { Understand and develop } \\
\text { product functions }\end{array}$ & $\begin{array}{l}\text { Function } \\
\text { structure }\end{array}$ & \multirow{2}{*}{$\begin{array}{l}\text { A3: Concept generation: Create } \\
\text { function structure and morphological } \\
\text { chart then generate concepts }\end{array}$} & \multirow[b]{2}{*}{3} \\
\hline 5 & Generate concepts & $\begin{array}{l}\text { Documentation } \\
\text { of concepts }\end{array}$ & & \\
\hline 6 & Develop concepts & $\begin{array}{l}\text { Selected } \\
\text { concept }\end{array}$ & $\begin{array}{l}\text { A4: Concept evaluation: Concept } \\
\text { descriptions and go/no go matrix }\end{array}$ & 4 \\
\hline 7 & Develop product & Product details & $\begin{array}{l}\text { A5-6: Concept evaluation: CAD } \\
\text { model and FEA/CFD }\end{array}$ & 5 \\
\hline 8 & Develop prototype & Prototype & $\begin{array}{l}\text { A7.1: Build and test: Test prototype } \\
\text { in competition setting }\end{array}$ & \\
\hline & Release documents & & $\begin{array}{l}\text { A7.2: Summary report: Summary of } \\
\text { design process }\end{array}$ & \\
\hline
\end{tabular}

Responses from students varied from 84 to 51 in a class of 88 students (Figure 5). Throughout all the surveys, 40 students participated in all five.

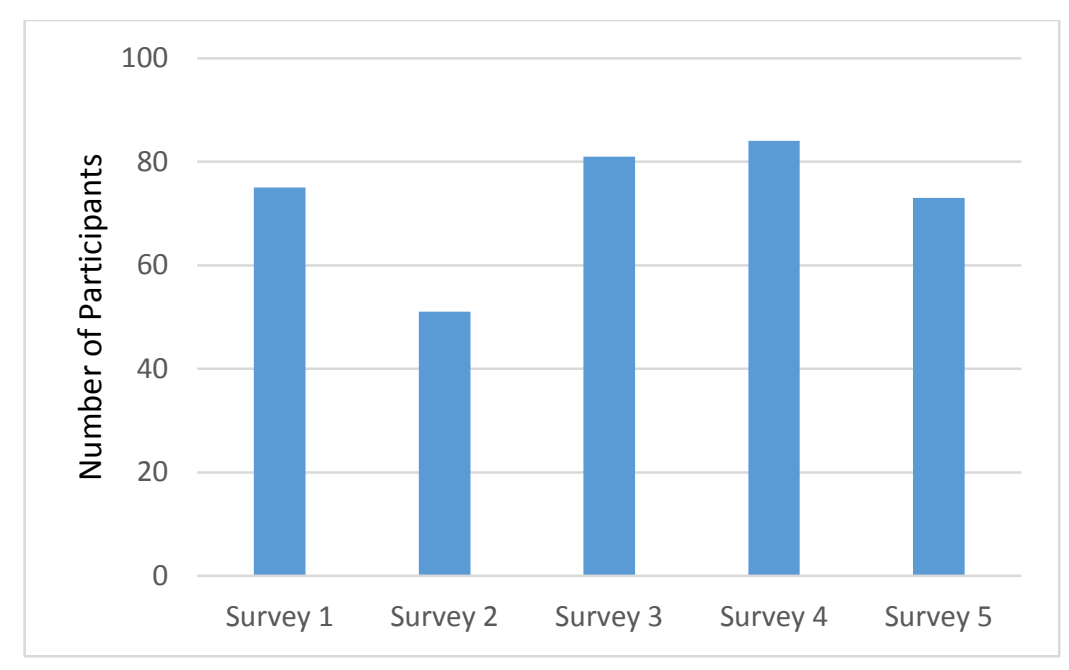

Figure 5: Distribution of student responses to survey

\section{Analysis of collected information}

In regards to students gaining the ability to understand requirements of an ill-structured problem (Figure 6), Question 1 shows some variation, but ends close to the initial. While Question 16, regarding the problem statement, has a steady increase followed by a large increase at the end. This large rise at the end could be the students gaining confidence as they build a prototype of 
their concept. They are realizing how the concept is meeting requirements of the design problem that they had identified much earlier in the process.

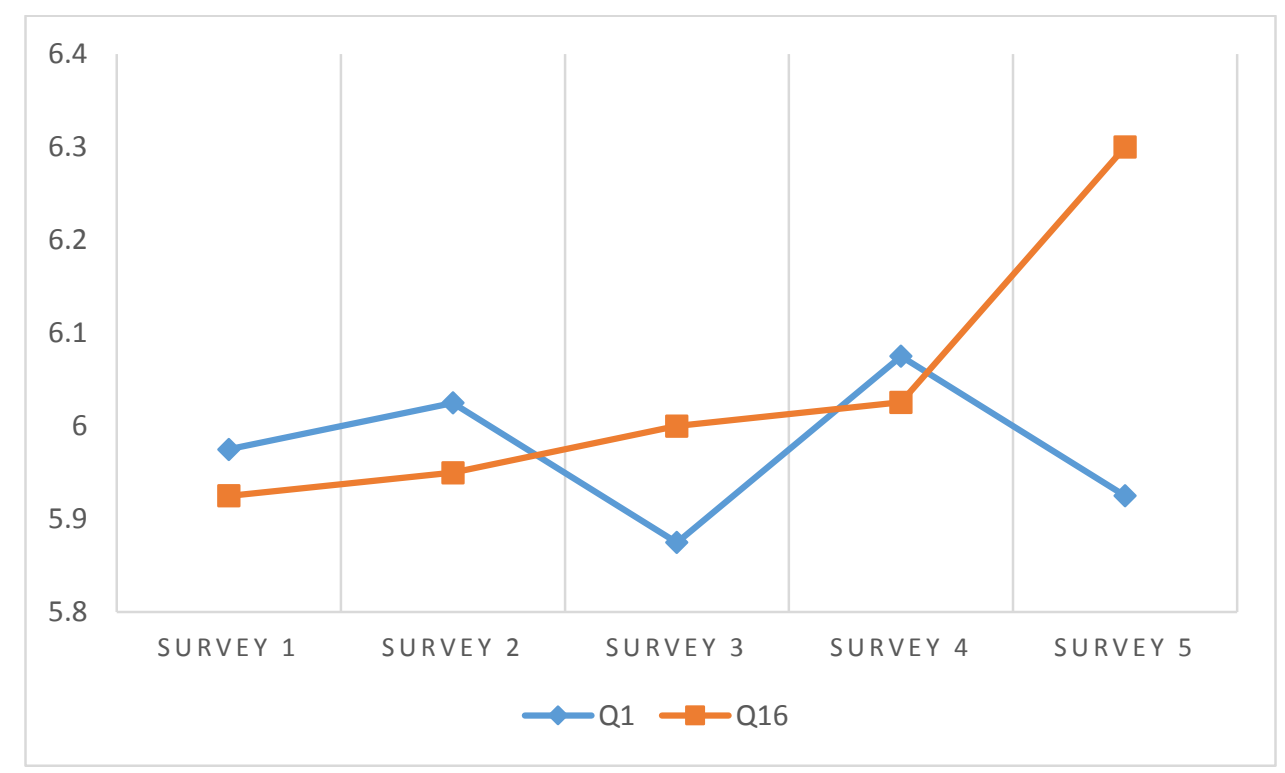

Figure 6: Responses to Understanding the Requirements

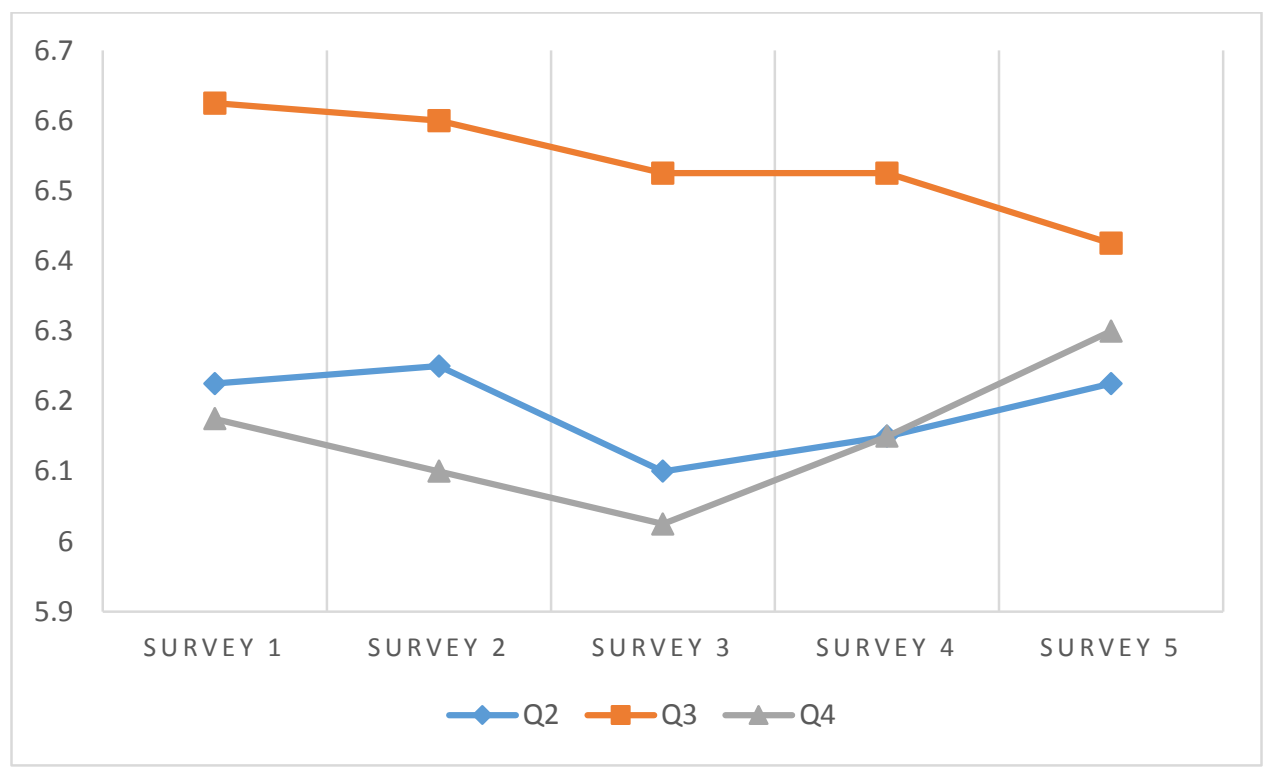

Figure 7: Responses to Managing a Team (Team) 


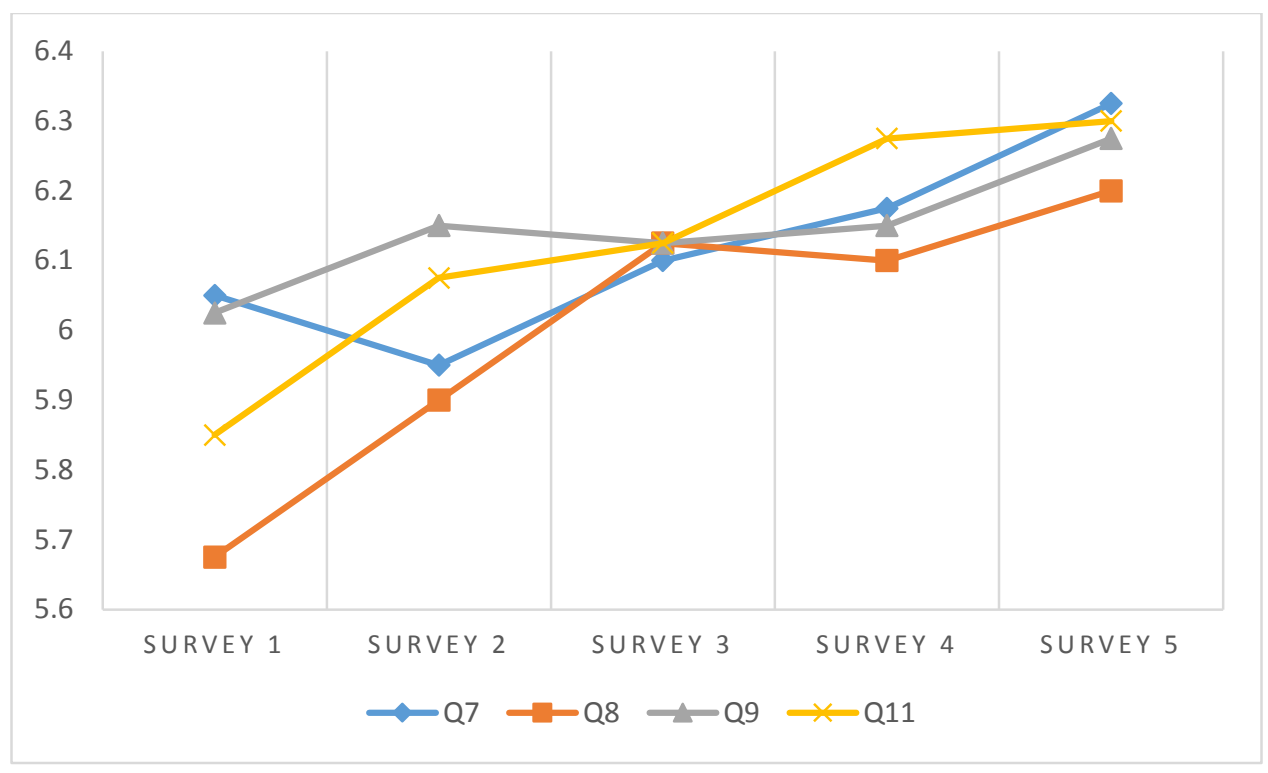

Figure 8: Responses to Managing a Team (Individual)

There was no statistically significant variation on students' perception of developed competencies related to managing a team (as a team) (see Figure 7). A slight dip occurred at Survey 3, but by Survey 5 they have recovered close to their level of competency at the beginning. On the other hand competencies related to managing a team (as an individual) had a steady increase throughout the semester (See Figure 8). This indicates that students, as individuals, learnt to organize and work in a group setting from the project.

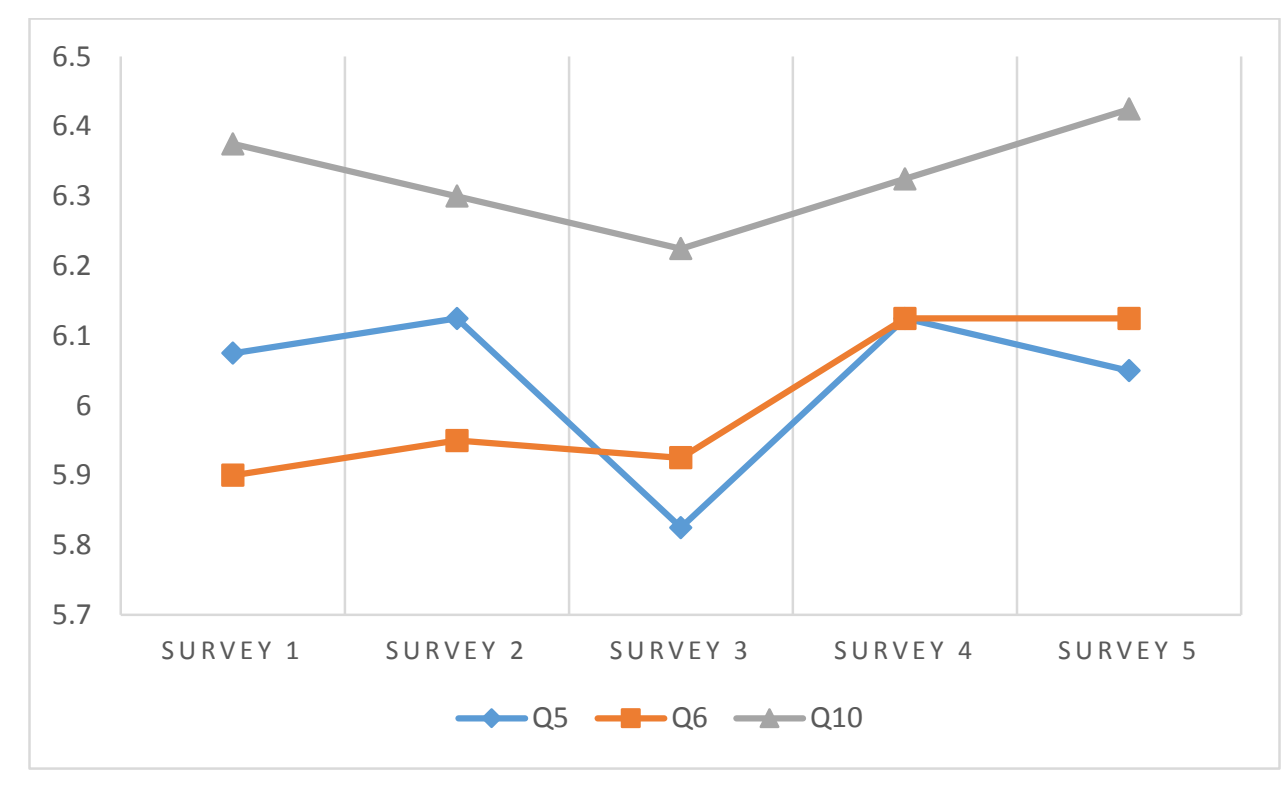

Figure 9: Responses to Communication

Responses to development of communication competency were also stable, with a dip during the third survey, followed by a rise as they work to gain the competency to the level that had originally proposed. 


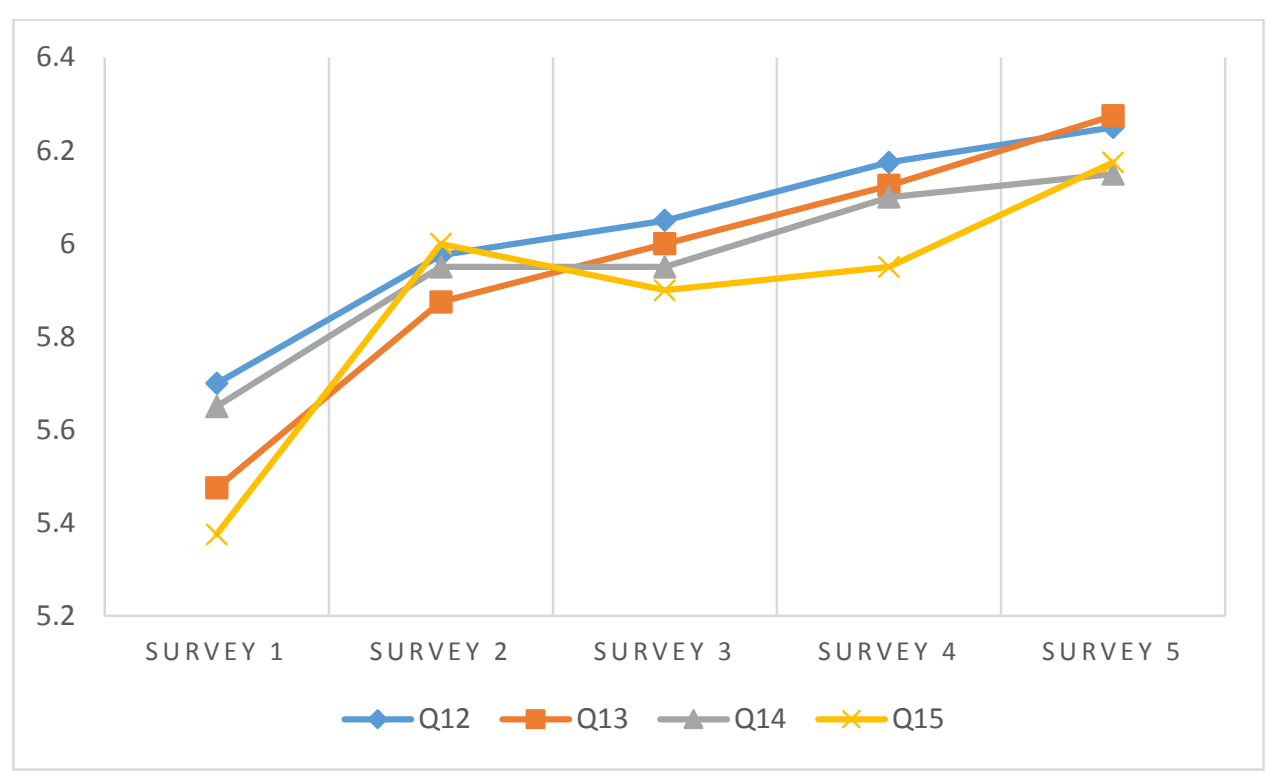

Figure 10: Responses to Understanding Design Process

Self-perception of competencies related to understanding the design process steadily increased throughout the semester. As the students worked through the design process they gained assurance that the design process they were following will lead to a successful project.

\section{Discussion}

The surveys were given as a self-reported evaluation of competencies and were not related to the grade in the class. This was done to prevent students from trying to report a higher level competency to receive a better grade. The data that has been collected sets a baseline for the class as we proceed to determine features and methods to teach and facilitate students to gain competencies.

From the collected data we observed that development of competencies do not follow the same trajectory. The trajectory for Development of Understanding the Requirements (Figure 6) shows a divergence for the two questions at the end (Survey 5). If there had not been multiple surveys through the semester we would have only seen a difference from the beginning to the end. By administrating the instrument multiple times during the semester we can see that students gained a better understanding of the problem statement at the end of the design process. This is most likely because students had started building the concept and were seeing areas in the requirements that they had missed or not encompassed. The ability to develop problem statement stays steady until Survey 5, and increases during Survey 5 as the students see the importance of a problem statement on the end product. Managing a team in a team setting did not have much variance through the semester. This may be because students had worked as individuals and combined the end work for an assignment, instead of working as a group. When looking at Figure 8 we see that students were able to improve on their competence in a team setting as an individual. Communication competence did not have a good sign of improvement from the data collected. This may be due to the students not focusing on this competency, but instead focusing more on the design. We saw a 
good increase in Understanding Design Process. This is most likely because of the focus the class has on working through the design process to develop and build a concept.

\section{Closing remarks}

Gleaning from the analysis of the data the following are suggestions on how to proceed with AME4163 in Fall 2015. To improve the course we recognize the need to clearly articulate the outcome we seek, namely, students internalizing the principles of designing via an authentic, immersive experience of designing, building and testing a mechanism. In Fall 2014 we introduced Project SHARK on day one of the class; students started to "design" with cursory attention to understanding the problem. In Fall 2105, we plan to release information on the design, build and test in week three of the semester. We plan to invest time on helping students internalize the importance of framing the problem by providing the students with examples of how a project can succeed or fail based on the framing. We believe this will lead to a gain in the competence of Understanding the Requirements. To help students with Managing a Team (Team) the importance of working congruently as a team needs a stronger focus. This entails rethinking the lecture and exercises. With Communication not showing much change the importance of communicating effectively in a team setting needs to be addressed as well. One possibility is to make communication a requirement in the Team Contract. We are considering creating a template for the Team Contract and scaffolding its completion.

The surveys can be improved by adding more items related to same competencies. This will allow us to determine the stability of different competency scales. A survey at the beginning of the semester, before the students have completed any work, can be administered to show confidence level of students related to their competencies from previous classes. Then as they proceed through AME4163, the surveys will track how students develop and reassess their competencies. In addition, student's motivation may have an impact on their competency development, which can be tracked by determining correlation between student motivation and competency development.

Some limitations of this work is the low amount of students that participated in all five surveys. The importance of participating needs to be emphasized to the students so that the data encompasses the class as a whole. Also the questions are limited to very particular competencies. Having questions that cover more competencies will allow us to see what all competencies the students are gaining through the course.

We are motivated and remain committed to explore the development of student competencies over time via an authentic immersive design experience. Clearly, what is embodied in this paper is work in progress. It is our hope that there are others in the engineering community who are interested in exploring this topic so we can form a community of educators who are keen to explore and learn as we move forward. 


\section{References}

1. Committee on Prospering in the Global Economy of the 21st Century, 2005, Rising Above The Gathering Storm: Energizing and Employing America for a Brighter Economic Future, Washington, D.C.: National Academy of Sciences.

2. Business Roundtable, 2005, Tapping America's Potential: The Education for Innovation Initiative, Business Roundtable: Washington, D.C.

3. Blue, C. E., Blevins, L. G., Carriere, P., Gabriele, G., Leader, S. K. G., Rao, V. and Ulsoy, G., 2005, The Engineering Workforce: Current State, Issues, and Recommendations. Final Report to the Assistant Director of Engineering., National Science Foundation: Arlington, VA.

4. National Academy of Engineering, 2004, The Engineer of 2020: Visions of Engineering in the New Century. National Academy of Engineering: Washington, D.C.

5. National Academy of Engineering, 2004, Educating the Engineer of 2020: Adapting Engineering Education to the New Century. National Academy of Engineering: Washington, D.C.

6. Lang, J. D., Cruse, S., McVey, F. D. and McMasters, J., 1998, "Industry Expectations of New Engineers: A Survey to Assist Curriculum Designers," Journal of Engineering Education, 88(1): p. 43-51.

7. Chubin, D. E., May, G. S., and Babco, E. L., 2005, Diversifying the Engineering Workforce. Journal of Engineering Education, 94(1): p. 73-86.

8. Siddique, Z., Hardré, P., Bradshaw, A, Saha, M, and Mistree, F., 2010, "Fostering Innovation Through Experiential Learning", ASME IDETC 2010, Montreal, Canada, DETC2010-28892.

9. Krathwohl, D. R., 2002, A Revision of Bloom's Taxonomy: An Overview. Theory Into Practice 41(4), 212218.

10. Christensen, C. M. and Raynor, M. E., 2003, The Innovator's Solution: Creating and Sustaining Successful Growth. Harvard University Press.

11. Allan, M. and Chisholm, C., 2008, Achieving Engineering Competencies in the Global Information Society through the Integration of On-Campus and Workplace Environments. Industry and Higher Education Journal, 2008. 22(3): p. 1-8.

12. Radcliffe, D. F., 2005, Innovation as a Meta-Graduate Attribute for Engineers. International Journal of Engineering Education. 21(2): p. 194-199.

13. Smith, W. F., Siddique, Z., Mistree, F., 2014, The Development of Competencies in a Design Course from a Student Perspective, $121^{\text {st }}$ ASEE Annual Conference \& Exposition 2014, Indianapolis, IN, 9046. Paper ID 9046. 